\title{
Mainstreaming EC in Africa: The EC facilitative re-granting program-Final narrative report
}

\author{
Jill Keesbury \\ Population Council \\ Wilson Liambila \\ Population Council \\ Youmane Niang Faye \\ Victoria Rumbold
}

Follow this and additional works at: https://knowledgecommons.popcouncil.org/departments_sbsr-rh

Part of the Demography, Population, and Ecology Commons, Family, Life Course, and Society Commons, Gender and Sexuality Commons, International Public Health Commons, Medicine and Health Commons, and the Women's Health Commons

How does access to this work benefit you? Let us know!

\section{Recommended Citation}

Keesbury, Jill, Wilson Liambila, Youmane Niang Faye, and Victoria Rumbold. 2009. "Mainstreaming EC in Africa: The EC facilitative re-granting program-Final narrative report." Nairobi: Population Council. 


\section{Mainstreaming EC in Africa: \\ The EC Facilitative Re-granting Program}

Final narrative report

Submitted to the Hewlett Foundation

By the Population Council, Nairobi Office

September 2009 


\section{Executive Summary}

Since 2006, ECafrique has been working to build the capacity of African non-governmental organizations (NGOs) to design, implement and evaluate successful EC mainstreaming projects. Through a process of "facilitative re-granting," ECafrique annually awarded nine grants ranging from $\$ 25,000$ to $\$ 30,000$ to organizations from across Anglophone and Francophone Africa. The program's objectives were to:

1) Increase access to EC across Africa by supporting projects intended to introduce, scale up or mainstream the method;

2) Build the capacity of African NGOs to design, implement and evaluate successful EC mainstreaming projects.

The Hewlett Foundation provided initial support for an intensive program of financial and technical assistance to three organizations each in 2007 and 2008. Additional funds from the Compton Foundation enabled the program to double the number of grants it provided in 2007, so that a total of six organizations from Anglophone and Francophone Africa received support in the program's first year. Each grantee participated in an international proposal development workshop, and received individualized technical support from ECafrique staff throughout the life of their project.

The nine projects supported under this program were:

- "Bridging EC users to oral contraceptives among young women at the University of Ghana."

- "Mainstreaming EC in three public sector health facilities in Kampala, Uganda."

- "Mainstreaming EC knowledge among in-service and pre-service health care providers in Uganda."

- "Expanding access to emergency contraceptive services in Oyo and Ogun States of Nigeria."

- 'Mainstreaming emergency contraceptive pills through public and private providers' network and community level structures in Suba District, Kenya."

- "Preventing unwanted pregnancies by introducing EC into the educational institutions of Pikine-Guediawaye, Senegal."

- "Provision of EC services to adolescents and survivors of sexual violence in Yaoundé, Cameroon."

- "Prevention of unwanted pregnancies among women living with HIV in the health districts of Baskuy and Boulmiougou, Burkina Faso."

- "Promotion of Emergency Contraception among youth aged between 15 and 24 years in five educational institutions in Cote d'Ivoire."

The following report details the accomplishments of each grantee, and highlights lessons learned regarding this approach to grant making. 


\section{Table of Contents}

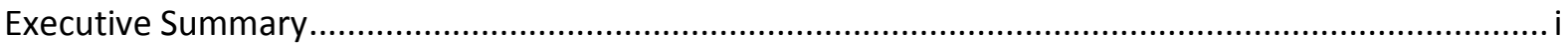

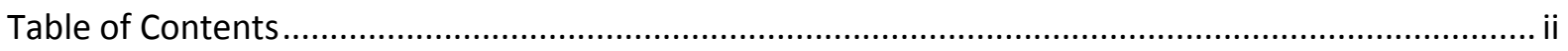

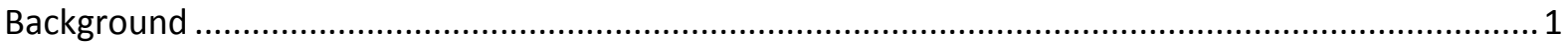

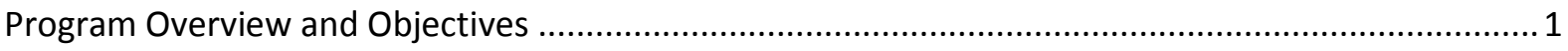

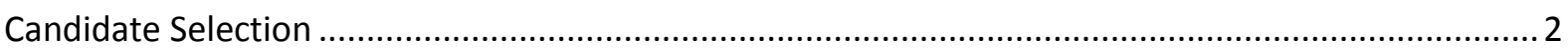

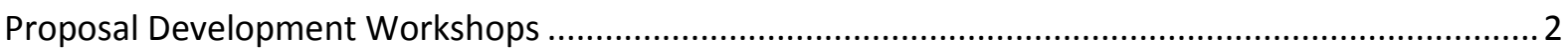

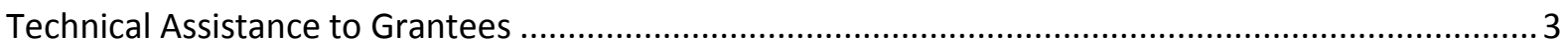

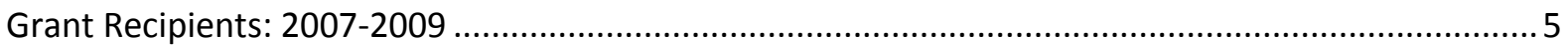

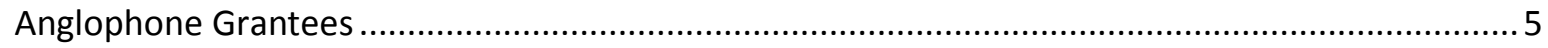

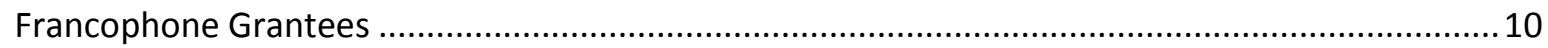

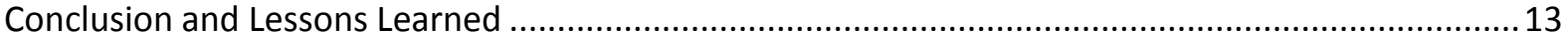




\section{Background}

For many women, emergency contraception (EC) offers a final opportunity to prevent unwanted pregnancy following method failure, rape or unprotected sex. While there is an on-going debate regarding EC's ability to reduce unwanted pregnancy and abortion rates at the population level, for individual women, access to this safe, effective option remains an essential element of their right to quality reproductive healthcare. However, EC remains inaccessible across much of the world, as both supply and demand constraints undermine potential clients' ability to obtain and effectively use the method. This is particularly true in developing countries, where limited commodity supplies, provider competency, public awareness and misinformation routinely coalesce to restrict EC availability.

ECafrique is a bilingual, international network of health care professionals, dedicated to building the knowledge and experience base needed to introduce, deliver and mainstream quality emergency contraception (EC) services in Africa. Established in 2003 under the auspices of the Population Council, ECafrique's membership today includes more than 1,000 institutions worldwide. The network seeks to foster dialogue on EC-related issues, particularly those relating to Africa. ECafrique publishes a regular bulletin in French and English, links network members with those of other regional EC networks, disseminates culturally appropriate service delivery tools, and develops new resource materials for improving and expanding the delivery of quality EC services.

\section{Program Overview and Objectives}

Since 2006, ECafrique has been working to build the capacity of African non-governmental organizations (NGOs) to design, implement and evaluate successful EC mainstreaming projects. Through a process of "facilitative re-granting," ECafrique annually awarded nine grants ranging from $\$ 25,000$ to $\$ 30,000$ to organizations from across Anglophone and Francophone Africa. The program's objectives were to:

3) Increase access to EC across Africa by supporting projects intended to introduce, scale up or mainstream the method;

4) Build the capacity of African NGOs to design, implement and evaluate successful EC mainstreaming projects.

The Hewlett Foundation provided initial support for an intensive program of financial and technical assistance to three organizations each in 2007 and 2008. Additional funds from the Compton Foundation enabled the program to double the number of grants it provided in 2007, so that a total of six organizations from Anglophone and Francophone Africa received support in the program's first year. This report reviews the achievements of the nine organizations that received support during the 2007-08 and 2008-09 grant periods. 


\section{Candidate Selection}

At the beginning of each grant cycle, a call for letters of interest was issued in English and French. In early 2007, this call was circulated through the ECafrique mailing list and included as part of the Compton Foundation's annual request for EC proposals. In 2008, a more aggressive dissemination strategy was employed and, with the assistance of the Hewlett Foundation and the Council's office of Public Relations, the call appeared in four reproductive health list-servs along with the greatly expanded ECafrique mailing list. This strategy was fruitful; in 2007, a total of 40 letters of interest were received while in 2008, 92 were submitted, 25 of which were in French.

These applications were reviewed in a three-stage process. First, ECafrique staff reviewed all letters of interest for eligibility, ensuring that they were submitted by African NGOs and included EC as a main programmatic component. Second, the eligible letters were sent to a team of independent reviewers with expertise in EC, with each application (both French and English) receiving three reviews. The independent experts were drawn from the active membership of ECafrique and represented universities, international organizations and partner NGOs. Finally, the ECafrique team tabulated results and made final selections from the top-rated applications based on the program's strategic interests, which included innovative approaches and geographic equity.

Following this review process, a total of six organizations per year were invited to one of the four proposal development workshops conducted in 2007 and 2008.

\section{Proposal Development Workshops}

The proposal development workshops represented the first element of the intensive technical assistance offered to grantees. While not all of the participants were ultimately funded under this program, the workshop was intended to help each group develop proposals that could be submitted to other donors, and to provide them with skills that would assist with future fundraising. Englishlanguage workshops were convened in Nairobi (April 2007, May 2008), and Frenchlanguage workshops took place in Dakar (May 2007, June 2008).

The workshop was conceived as a minicourse on proposal development, which enabled participants to refine their initial letters of interest

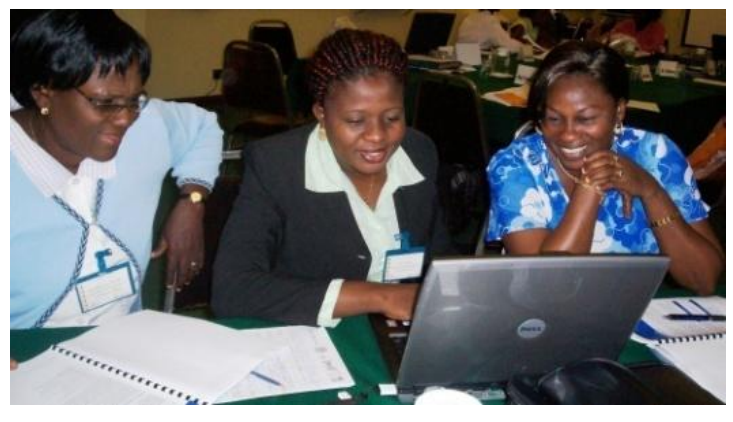

Participants at Nairobi proposal development workshop into the strongest possible project proposals, incorporating realistic goals, a well-specified strategy for implementation, and achievable methods for measuring impact. The logical framework approach guided the proposal development process. 
ECafrique developed a curriculum specifically for this course, and participants were provided with the International Planned Parenthood Federation's "Guide for designing results-oriented projects and writing successful proposals" (available in English and French). Participants were also given an information folder and CD containing resources on EC, both general and tailored to the specifics of their respective projects. These materials and curriculum have been successfully adapted for use in other programs, and the training has been replicated by several participants in their own countries.

The workshops placed emphasis on "bridging" users of EC to regular contraceptive methods and other reproductive health services. The importance of project sustainability was also stressed during the workshops and so the grantees were required to consider - and include in their proposals - details of how their programmatic influence would extend beyond the one-year project duration.

Confidential evaluations conducted at the end of each workshop were unanimously positive, with the quality of workshop content and process mostly rated "excellent". Suggestions that the workshop duration be prolonged to five days, to allow sufficient time to prepare high-quality logical frameworks and budgets, were adopted for the 2008 workshop. The participants also noted that they benefitted from the opportunity to share experiences with other organizations working to mainstream EC.

Following the workshops, ECafrique staff continued to assist participants in refining their proposals over email and telephone.

\section{Technical assistance to grantees}

Once grantees were selected, ECafrique supported these programs through on-going technical assistance throughout the life of the grants. Because many of the grantees had no prior experience with EC, this technical assistance emerged as the most important and intensive element of the program.

Each grantee received at least one on-site support visit from ECafrique staff, and regular communication was maintained over email and telephone. These support visits allowed ECafrique representatives to assess performance, address arising issues, and offer hands-on assistance in matters ranging from the facilitation of training workshops, the development of IEC materials, and the design and execution of M\&E. Liaison and networking enabled organizations to create strategic linkages, which in turn increased the capacity and extended the influence of the EC projects. For example, in Uganda, where EC supplies have been erratic and widely unavailable, ECafrique was able to advocate for improved access in the public sector and create strategic linkages between the two grantees in-country.

Provision of this assistance was coordinated by the ECafrique secretariat in Nairobi, with the Dakar office providing day-to-day support to the francophone grantees in Senegal and Cameroon and the Council's Abuja and Accra offices providing additional support to incountry grantees. 
An additional benefit to grantees is the ECafrique virtual resource library www.ecafrique.org - which includes IEC materials, training guides, EC provision guidelines and research papers; all downloadable for use and reference by grantees. Also contributing to the body of knowledge on EC are the case studies commissioned in Nigeria, Senegal and Uganda, which have in turn been incorporated into a synthesis paper of African 'lessons learned' on the mainstreaming of EC. This paper is currently under review at a regional journal.

To ensure the continuity and sustainability of partner projects, ECafrique has supported grantees' efforts to leverage future funding. Program staff assisted two partners (CC\&RP and CESRAF/ALVF) in preparing proposals for the European Society of Contraception, one of which was successful. ECafrique has also actively lobbied the International Planned Parenthood Federation, USAID and UNFPA for greater support to the francophone grantees.

The network has also encouraged and supported the dissemination of program results. National disseminations were held in Uganda, Nigeria, Senegal and Cameroon, which were widely attended by policymakers and key stakeholders. The Senegalese grantee, CEFOREP, presented project results at the 2008 Congrès de Société Africaine de Gynécologie et Obstétrique in Mali. Both Ugandan grantees, CC\&RP and AOGU, have presented their projects at regional conferences. 


\title{
Grant Recipients: 2007-2009
}

In 2007, ECafrique was able to provide funding to all six of the organizations that attended the proposal development workshops, through the generous support provided by both the Hewlett and Compton Foundations. In 2008, three of the six groups received direct financial support from ECafrique, while the remaining three were encouraged to submit their proposals to other donors.

Grants ranged between $\$ 25,000$ and $\$ 35,000$ and were implemented over a period of approximately one year. While the 2007 grants have ended, each of the 2008 grantees have requested no-cost extensions to allow them to complete program activities. Based on prior discussions with the Hewlett Foundation, the final payment on these grants will be made in late 2009 using other Foundation funds provided to ECafrique. The main accomplishments of each grantee are outlined below.

\section{Anglophone Grantees}

\author{
Country: $\quad$ Ghana (2008 award) \\ Project Title: $\quad$ Bridging EC users to oral contraceptives among young women at the \\ University of Ghana \\ Organization: $\quad$ Ghana Social Marketing Foundation (GMSF) International
}

GSMF International is a fully Ghanaian-owned not-for-profit organization incorporated in Ghana in May 1993. It is dedicated to socially marketing health and reproductive health products through a nationwide infrastructure, and introduced a dedicated EC product into its product range in 2008. The goal of this project is to improve access and use of EC among young women aged between 18 and 30 years in the University of Ghana and to increase the uptake of co-marketed oral contraceptive pills among young women who access EC through pharmacies in and around the University.

The project began by undertaking formative and baseline research on EC use in the University Community. Research instruments were developed by GSMF in association with a local research agency in December 2008. Four focus group discussions were conducted with both female and male discussants from halls of residences on campus and some hostels outside the university campus. Ten (10) in-depth interviews were conducted with students, student leaders, health professionals and some authorities of the university. As part of the FGDs, participants were asked to picture the EC pill as a person and to describe what kind of person they thought she or he would be. The responses given included:

- "Someone you can count on"

- "Middle-aged man with a lot of experience"

- "He is a lawyer, doctor, teacher"

- "Usually found on university campuses"

- "He hangs out in night clubs and at parties"

- "A close friend of sexually active young ladies". 
These responses indicated the perception the discussants had about EC pills. Generally, EC pills are viewed as a safety net.

A quantitative survey was also conducted to obtain data to be used as baseline indicators and for the assessment of the success of the project. One hundred and ten (110) respondents were interviewed. Results showed that, generally, university students had heard about emergency contraception, but had inadequate or incorrect information about its operation and use. About half (47\%) of respondents who knew about EC thought they were most effective within the first 72 hours following unprotected sex. Only $2 \%$ knew that it could be effective up to 120 hours after unprotected sex. About $49 \%$ of respondents indicated that they had used EC pills prior to the baseline survey, and of these, $55 \%$ said they used it as a back-up/ precautionary measure. About $38 \%$ said they failed to use any contraceptive method before/during sex and $49 \%$ of those who had used EC mentioned that it was recommended by their partner, while $32 \%$ mentioned their friends as those who recommended EC.

From the results of the baseline survey, messages were developed to address the information needs of the target population. The campaign includes leaflets, handbills and posters, which were distributed to the target population, educating them on simple facts about EC and disseminating information relevant to the intervention. Examples of these materials are shown below, and can be found on GMSF's project website: www.ecgsmf.com
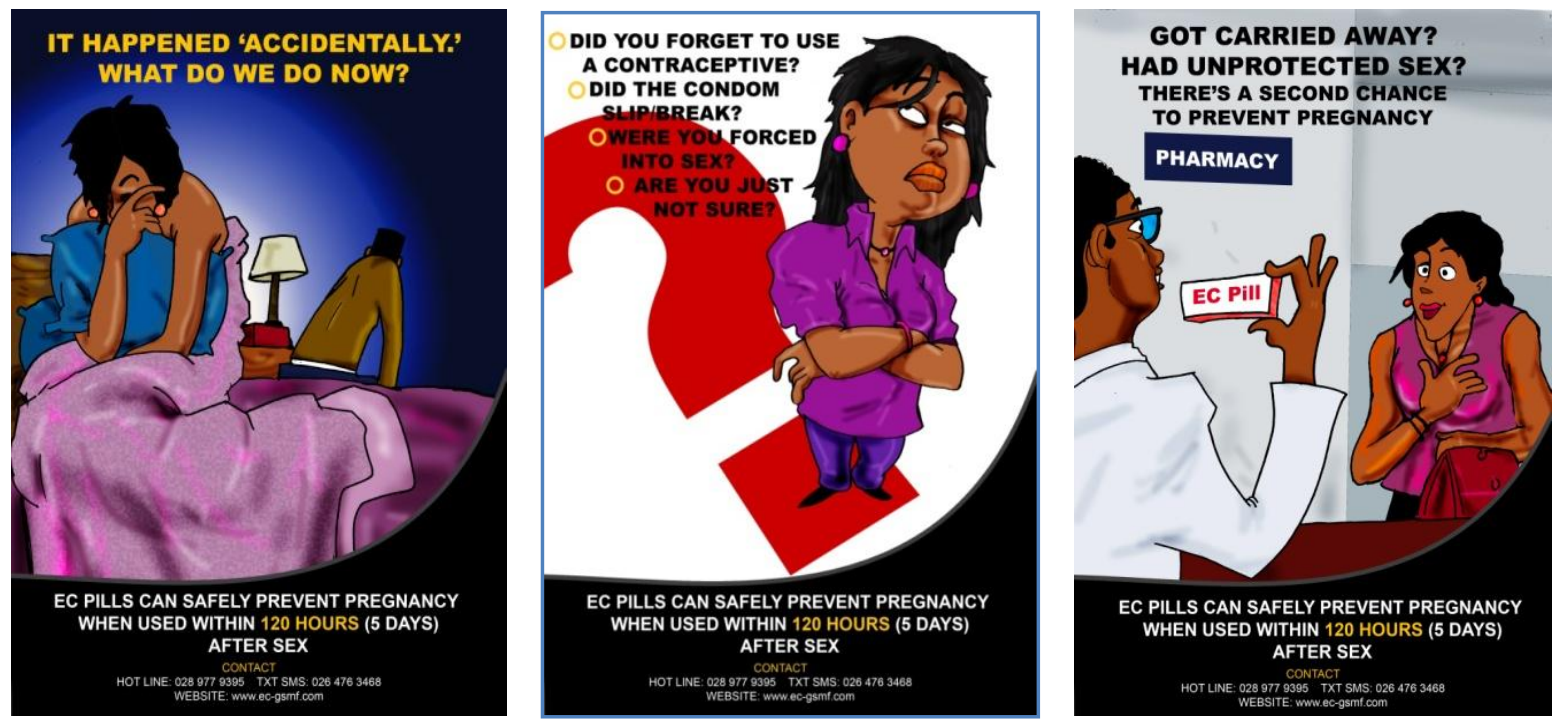

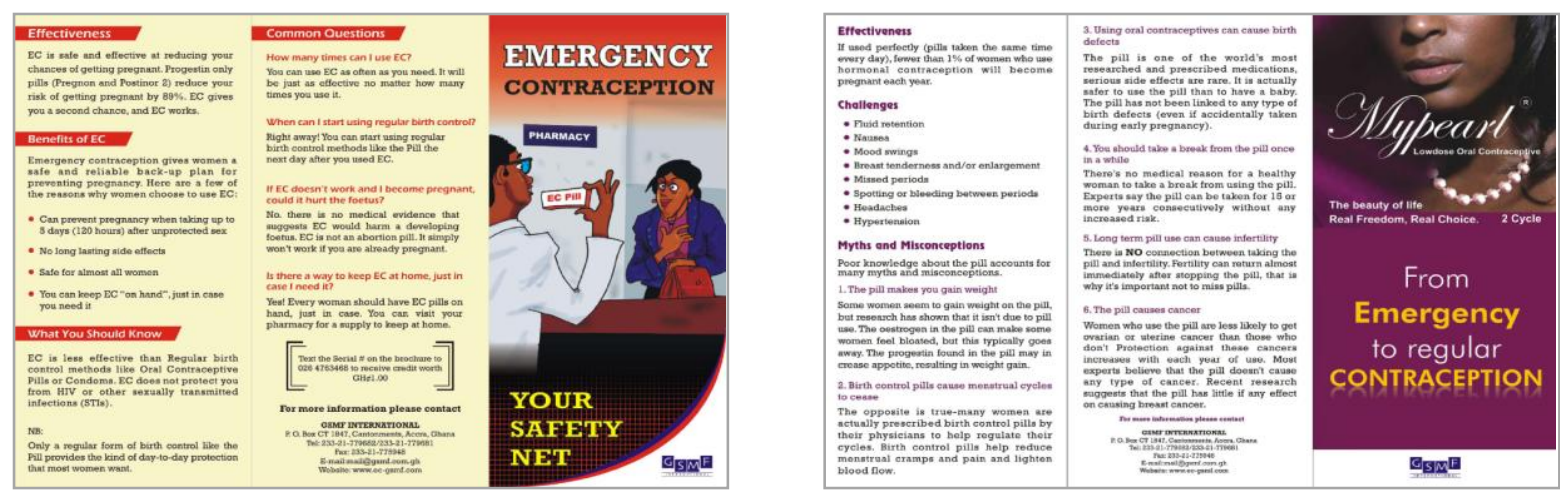

This project will conclude in December 2009, and its impact will be measured through an endline survey.

Country:

Uganda (2007 award)

Project title:

Mainstreaming EC in three public sector health facilities in Kampala

Organization:

Child Care \& Rescue Programme (CC\&RP)

The objective of the CC\&RP project was to increase awareness and access to EC among adolescents in two public health divisions of Kampala. Under the program, CC\&RP conducted intensive training and sensitization on EC among health providers and community members and sought to improve the procurement and availability of EC and contraceptive supplies. Information, education and communication (IEC) materials, with an emphasis on male involvement, were designed and distributed nationwide, and also made

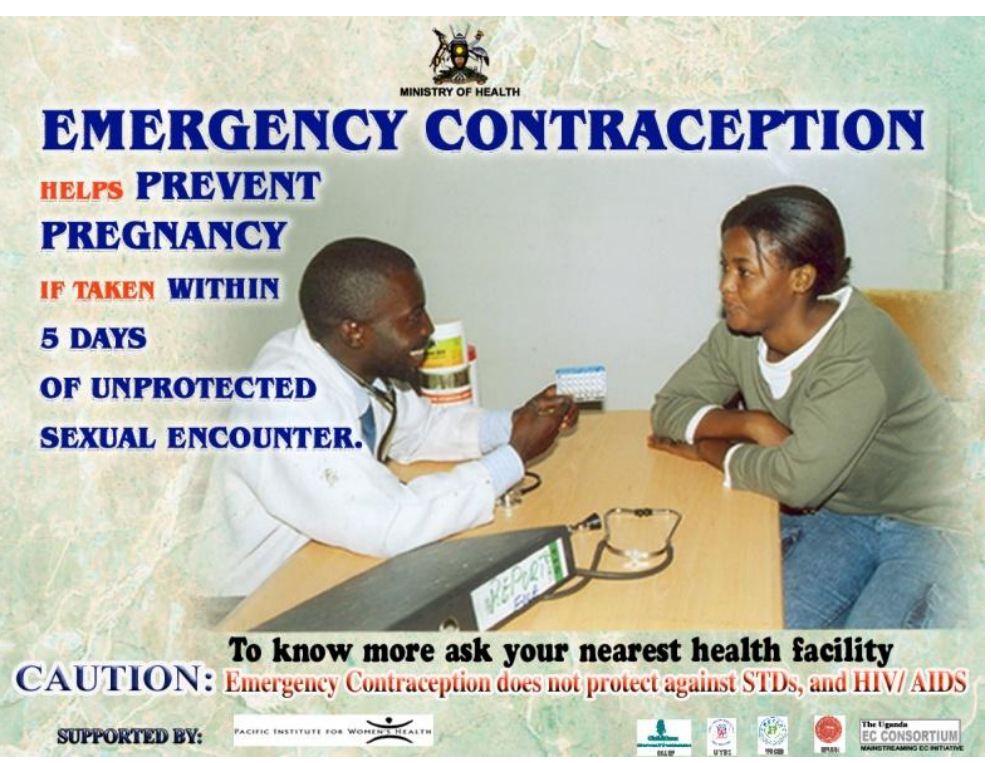
available to other organizations for future use. The program also worked to ensure supply of longacting contraceptive methods in participating health facilities, in order to facilitate the transition from EC to more consistent protection.

To ensure the sustainability of the program's achievements, advocacy meetings were conducted with the Ministry of Health $(\mathrm{MOH})$ and other organizations influential in the reproductive health $(\mathrm{RH})$ field.

These meetings addressed important issues such as the procurement and availability of EC and the inclusion of an EC column in the FP register to ensure collection of accurate statistical information on EC. ECafrique representatives supported CC\&RP in lobbying the $\mathrm{MOH}$ for improved access to government stocks of EC, and effected strategic introductions to other organizations with EC-oriented programs, including the Association of Obstetricians \& Gynecologists of Uganda (AOGU). 
Over the life of the project, orders of EC from participating facilities increased dramatically, which was partially attributed to changes associated with better recording of EC clients at the health centers. Service providers trained under the project were also able to provide the Yuzpe regimen of EC which allowed them to continue providing the method in the face of frequent product stock-outs. Uganda remains consistently challenged with stock-outs of a dedicated EC product and limited public awareness.

With support from ECafrique, CC\&RP has successfully obtained additional support for its EC program from the European Society for Contraception. Results of this project were also presented at a regional conference on Sexual and Gender-based Violence held in Nairobi in October 2008.

\section{Country: Project title:}

Organization:
Uganda (2008 award)

Mainstreaming EC knowledge among in-service and pre-service health care providers in Uganda

The Association of Obstetricians and Gynecologists of Uganda (AOGU)

AOGU is a professional organization that represents over 120 specialists in obstetrics and gynecology in Uganda. It has shown leadership in promoting EC, and a senior member has conducted the most recent and extensive study on EC in the country. ${ }^{1}$ This study indicated that only 8 of every 10 health care providers have heard about EC, including staff from nurses/midwives and medical school training institutions across Uganda. These providers also demonstrated a number of misperceptions about EC.

Capitalizing on its involvement in training current and future $\mathrm{RH}$ service providers, AOGU has initiated a program intended to provide in-service training to nurses, paramedics and midwives in 2 national referral hospitals and 11 regional referral hospitals. The organization will also integrate EC into the curriculum of 15 training institutions nationwide, including 4 medical schools and 11 nursing training schools.

To date, AOGU has trained approximately thirty trainers-of-trainers (TOTs), including tutors and professors from the selected training institutions. Pre- and post-test results demonstrated high levels of knowledge acquisition following the trainings.

Participants have also developed action plans for further training in their home institutions. AOGU will support the implementation of these action plans throughout the life of the project, which is set to conclude in late 2009. To assess the impact of the trainings, AOGU will conduct a final survey of the providers at the targeted institutions.

\footnotetext{
${ }^{1}$ Byamugisha JK et al. 2006. Emergency Contraception and Fertility awareness among University Students in Kampala, Uganda. African Health Sciences 6:4 (194-200).
} 

Country:
Nigeria (2007 award)
Project title:
Expanding Access to Emergency Contraceptive Services in Oyo and Ogun States of Nigeria
Organization:
Association for Reproductive \& Family Health (ARFH)

ARFH worked to increase the availability and awareness of EC among sexually-active young people (aged 15-24) by strengthening the capacity of Patent Medicine Dealers (PMDs) to provide EC information and services. ARFH purchased and distributed ECPs to the PMDs, who retained a proportion of the profits as an incentive. IEC materials were developed, pre-tested and distributed to supplement awareness-raising activities. Clients were counseled and where appropriate, provided with ECPs and referred for regular family planning methods. As part of this project, referral links were established between the chemists and local health facilities.

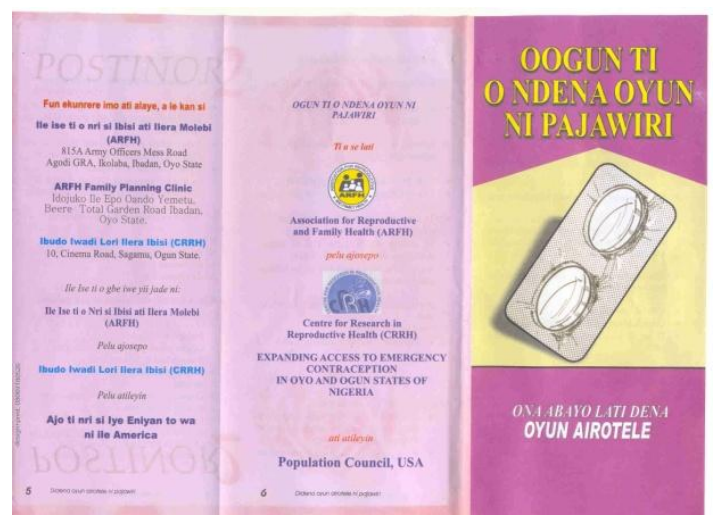

A strong emphasis on advocacy and networking at all levels enabled the project to overcome conflicting policies regarding the provision of EC pills by chemists, and secured the involvement and active support of both state and community officials. In Oyo state, the inauguration of project advisory committees and involvement of a community pharmacist to coordinate PMD activities established a valuable precedent for increasing access to EC in other states.

Support for this project was provided by Population Council staff in Abuja, who assisted with evaluation design and routine monitoring activities.

\section{Country: $\quad$ Kenya (2007 award) \\ Project title: $\quad$ Mainstreaming Emergency Contraceptive Pills through Public \& Private Providers Network and Community Level Structures in Suba District \\ Organization: $\quad$ Centre for the Study of Adolescence (CSA)}

CSA's strategy to increase the knowledge, acceptability and accessibility of EC among women in Suba district involved the mainstreaming of EC within RH service delivery in both the public and private sectors. The first phase of the project focused on the sensitization of district officials and health facility staff, and the training and mobilization of both facilitybased health workers and community-based health workers (CBHWs), who in turn conducted awareness-raising in their communities. To ensure the effective distribution and availability of ECPs, CSA provided logistical support to the $\mathrm{MOH}$ by distributing contraceptive supplies to health facilities, often combining these trips with monitoring visits, using tools developed in collaboration with ECafrique staff. 
This strategy strengthened linkages with the $\mathrm{MOH}$, increased the capacity and knowledge of health providers, and improved awareness and availability of EC in health facilities in the Suba district. The sustainability of the project is ensured by the training of a substantial body of health providers and CBHWs who will continue to disseminate their knowledge. An observed pattern of high incidence of both consensual and coerced sexual activity among young people in Suba highlights the need for further research on how EC can potentially influence adolescent sexuality and reproductive health.

\title{
Francophone Grantees
}

\author{
Country: \\ Senegal (2007 award) \\ Project title: \\ Preventing unwanted pregnancies by introducing EC into the \\ educational institutions of Pikine-Guediawaye \\ Organization:

\section{Centre Regional de Formation et de Recherche en Santé de la} \\ Reproduction (CEFOREP)
}

CEFOREP resolved to tackle the high prevalence of unwanted adolescent pregnancies by improving knowledge and awareness of EC in the school environs of the Guediawaye district. The project developed training tools and IEC materials and trained a wide crosssection of formal and informal providers in the district, including health providers, pharmacists, pharmacy assistants and CHWs. Sensitization meetings, designed to increase awareness of EC and to highlight the risks of certain sexual behaviors, were conducted among students and teachers.

A knowledge, attitudes and practice (KAP) study conducted among formal and informal providers at the end of the project found an improvement in both perception and knowledge of EC methods, and an appreciation of EC's role in preventing unwanted pregnancies, particularly for survivors of sexual violence. However, religious and cultural reservations remain, particularly concerning adolescent use of EC. There is wide support for using the provision of EC as an opportunity to bridge clients to regular contraceptive methods and approval for including EC in the 'basket' of contraceptives.

Interestingly, young couples most frequently present to pharmacies to obtain EC, with men tending to provide the cash for procuring the method. The majority of users are above the age of 24 - perhaps reflecting the high cost of the dedicated EC product Norvleo in pharmacies. Provider training, sensitization of adolescents and the improvement of EC access and availability have been identified as key focus areas for future activities, and there is also need to introduce an effective data-capturing system to monitor EC use in the public sector.

The results of this project were presented at the December 2008 Society of Obstetricians and Gynecologists (Congrès de Société Africaine de Gynécologie et Obstétrique) meeting held in Mali, and have been accepted for presentation at the International Conference on Family Planning to be held in Uganda in November 2009. 


\section{Country: \\ Project title:}

Organization:
Cameroon (2007 award)

Provision of EC services to adolescents and survivors of sexual violence in Yaoundé

Centre d'Ecoute et de Conseils de Santé Reproductive des Adolescent(e)s et des Femmes; Association de Lutte contre les Violences Faites aux Femmes (CESRAF/ALVF)

CESRAF and AVLF worked together to improve the quality of EC services available to adolescents and survivors of sexual violence, and to develop the capacity and skills of health providers. A knowledge, attitudes and practice (KAP) study conducted early in the project among health providers and the general population showed low knowledge and awareness of EC, and that EC services were rarely offered at health centers. The project tackled these challenges by training both health providers and $\mathrm{CHWs}$ on the provision of $\mathrm{EC}$, and holding sensitization meetings which reached 2,700 adolescents and adults.

The project management made a strategic decision to also include pharmacists in the training, after they discovered that the majority of enquiries about unintended pregnancies are directed to pharmacies. The project enlisted other institutions to popularize EC, and conducted regular monitoring and support visits to the health providers and CHWs. "EC kits", each containing 4 EC units, 1 IUD, 10 female condoms and 100 male condoms, were distributed, on request, to the health providers, which were in turn sold to clients, with the exception of those given to survivors of sexual violence.

Few EC resources exist in the French language, and CESRAF developed several materials which can be used in subsequent projects. These included guidelines for health providers on prescribing EC, with a protocol on sexual assault care; an EC counseling guide for community health workers (CHWs) and community leaders; and IEC materials for the general public in the form of a poster and brochure. These materials were developed in conjunction with ECafrique staff in Dakar, and based on information developed by the $\mathrm{MOH}$ in Senegal for training health care providers on EC.

\section{Country: $\quad$ Burkina Faso (2007 award) \\ Project Title: $\quad$ Prevention of unwanted pregnancies among women living with HIV in the health districts of Baskuy and Boulmiougou \\ Organization: L'Association Vivant Ensemble (AVE)}

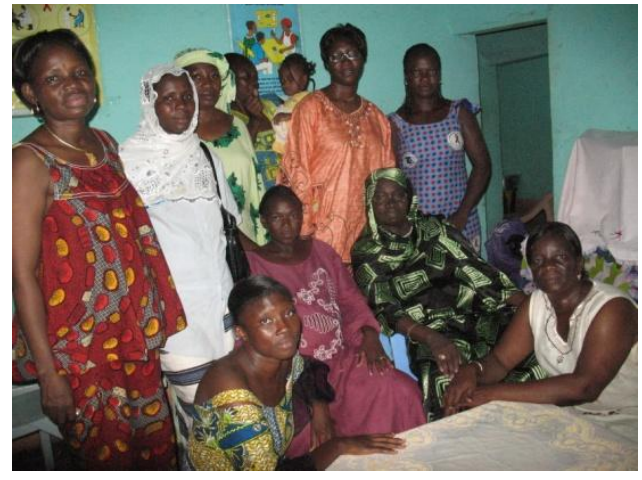

Community home visitors
This project focused on increasing the knowledge of women living with HIV of contraceptive options, including EC, and on improving access to these methods. Domestic visits to women living with HIV, and to uninfected women, alongside a sensitization strategy, helped to increase awareness of EC and to provide women with the skills to negotiate dual protection with their sexual partners. Nearly 5,500 persons were directly exposed to EC information in 
thrice-weekly meetings conducted by the health teams. Health providers and members of the community teams were trained on EC and dual protection, and a multi-disciplinary scientific committee was established to support and promote EC-related activities. Radio spots sought to raise further awareness of family planning and emergency contraception. EC kits were distributed among the sites and during the domestic visits to women living with HIV.

\author{
Country: $\quad$ Cote d'Ivoire (2008 award) \\ Project title: $\quad$ Promotion of Emergency Contraception among youth aged between \\ 15 and 24 years in five educational institutions in Cote d'Ivoire \\ Organization: $\quad$ Agence Ivoirienne de Marketing Social (AIMAS)
}

AIMAS was the only West African participant in the 2008 competition that qualified to receive financial support. The project aimed at improving the acceptability of EC by youth aged between 15 and 24 years in five educational institutions in two towns of Côte d'Ivoire.

The project focused on creating awareness through interpersonal communication activities in the target schools. The project began by training peer educators and supervisors in Abidjan and Agboville, who were then charged with communicating these messages within the school communities. Through these peer educators, a total of 53 community animations were conducted under the project, which reached a total of 4,130 youth. Through other school-based activities, a total of 16,955 students, of which 11,309 were girls and 5,646 were boys ages $15-24$, were reached by the program. This figure far exceeds initial targets.

These accomplishments have been realized despite both teacher and student strikes, which disrupted the training and communication activities.

Some of the lessons learnt included the fact that promotion of EC in schools was of strong interest to head teachers of private schools, who are concerned by high student drop-out rates due to pregnancy. The project was widely appreciated by the stakeholders and there was a general consensus that the project should be continued in upcoming years. 


\section{Conclusion and Lessons Learned}

As indicated above, the program successfully supported nine local organizations in their efforts to mainstream EC across Africa. Just as importantly, it created a strong and committed group of EC advocates in eight countries and has increased the visibility of EC across the region. The lack of such an interest group, especially in West Africa, has been widely believed to be an important deterrent to expanding access to EC.

ECafrique will continue to support these partners in order to ensure the sustainability of their efforts. This includes creating partnerships to consolidate and extend the influence of the project, and using their proposal development and networking skills to actively seek future donors.

As a model of small grant-making, this program offers several lessons:

- The proposal-development workshops were widely regarded as creating a strong foundation for the subsequent projects, not only because they enabled ECafrique to select the strongest candidates and strategies, but because they encouraged grantees to consider every aspect of a prospective project - without dampening innovation - which resulted in proposals that met international standards. Many participants reported sharing the knowledge acquired during the workshops with other colleagues, thus achieving a cascade effect of capacity-building. This fostered new partnerships that consolidated and extend the influence of the project, and help participants employ their proposal development and networking skills to actively seek future donors.

- Technical assistance has played a critical role in the successes of this small grants initiative, and the consistency and quality of support is directly correlated to the ability of individual projects to achieve their objectives.

- Management challenges were frequently related to delays in the submission of documentation or reports. These were overcome by providing all grantees with a tailored calendar detailing donor requirements and deadlines.

- A degree of programmatic flexibility is beneficial, both to cater for unforeseen circumstances, and to allow projects to use their acquired skills to respond creatively to local needs. However, one significant benefit of the proposal development workshops lies in the opportunity to encourage applicants to consider all eventualities in advance, paying particular attention to legal and regulatory requirements, and the need to enlist the support of stakeholders.

- Efficient monitoring and evaluation remain a crucial aspect of a project on any scale. Each grantee was assisted in the development and implementation of a monitoring strategy, although significant challenges in measurement were still encountered. One frequent challenge was the inadequacy or inexistence of health information systems able to capture data on the utilization of EC, along with staff that were inexperienced in conducting project monitoring activities. 